\title{
O Processo de Integração Regional: Fronteiras Abertas para os Trabalhadores do Mercosul*
}

Sonia de Camargo**

\section{Introdução}

O tema da livre circulação de pessoas nos processos de integração regional faz parte de uma agenda social que inclui, além das questões ligadas diretamente ao trabalho, várias outras, entre as quais as referentes ao direito de residência em qualquer um dos países do bloco e à proteção aos seus dependentes, assim como condições relacionadas com o livre exercício profissional, técnico, científico ou liberal. Devese assinalar ainda que o tema da liberdade de acesso aos postos profissionais e de trabalho se torna cada vez mais presente, e não apenas na esfera regional, na medida em que o fenômeno crescente da globalização em âmbito internacional, ao diluir fronteiras que podem prejudicar a disputa por mercados, tende a tornar os obstáculos baseados na nacionalidade, matéria crescente de reflexão, discussão e conflito.

Neste artigo, limito-me a discutir a liberdade de circulação de pessoas

\footnotetext{
* Artigo recebido em outubro e aprovado para publicação em dezembro de 2010.

** Doutora em Ciência Política pela Universidade de São Paulo (USP) e professora emérita do Instituto de Relações Internacionais da Pontifícia Universidade Católica do Rio de Janeiro (IRI/PUC-Rio). Email: scamargo@puc-rio.br.
} 
na esfera regional, especificamente de trabalhadores no âmbito do Mercosul. Proponho-me, assim, a examinar de que maneira este bloco tem lidado com essa temática, descrevendo as condições e o cenário onde estes circulam ou deverão poder fazê-lo livremente em algum momento do processo de integração em que estão inseridos. Já é possível dizer que esta liberdade, que vem acompanhada, obrigatoriamente, pelo direito de residir no país em que passarão a exercer seu ofício e de receber proteção para exercê-lo com dignidade, tem avançado significativamente, o que leva a prever que o Mercosul está mais próximo do objetivo de se constituir como um mercado comum, por tanto tempo adiado. ${ }^{1}$

Posterior ao projeto Mercosul, ou melhor, dando maior dimensão a este projeto, uma outra meta mais ambiciosa tem atraído o interesse de alguns governantes e pesquisadores. Trata-se da ideia de que a própria América do Sul deve caminhar, em um futuro ainda não claramente previsto, para a integração de todo o seu território, de acordo com a proposta formulada na Declaração de Cuzco, apresentada na III Reunião de Presidentes do Mercosul, em 8 de dezembro de 2004, quando foram lançadas as bases para a constituição de uma Comunidade Sulamericana de Nações. Ampliando esta primeira proposta, que tinha como embrião a união entre o Pacto Andino e o Mercosul, foi apresentado em maio de 2008 um novo projeto, a formação da União de Nações Sul-americanas (Unasul), que, incorporando à proposta anterior a Guiana e o Suriname, deveria se tornar um bloco suficientemente forte para se constituir como uma alternativa à Área de Livre Comércio das Américas (ALCA) (ROMERO, 2008). ${ }^{2}$

É preciso, contudo, lembrar que, se nos debruçarmos sobre o atual panorama sul-americano, em que questões políticas e sociais, além das econômicas e de segurança, dificultam a aproximação entre seus governos e suas sociedades, vemos que a perspectiva de se construir um espaço regional integrado, no qual as fronteiras entre os Estados se tornem rotas abertas para seus cidadãos em geral e para os trabalhadores em particular, não é uma tarefa fácil.

Com efeito, se tomarmos como tema básico de reflexão as dimensões política e econômica da América do Sul, nos deparamos com um con- 
texto em que a diversidade de formas de governo, algumas avaliadas como conservadoras, outras como progressistas, dificultam soluções convergentes ou negociadas e no qual a diferença entre os níveis de desenvolvimento de seus países cria obstáculos difíceis de serem ultrapassados. Na realidade, os diferentes governos, ao enfrentarem o desafio de conduzir e administrar sociedades interna e externamente desiguais e modalidades de inserção regional e internacional próprias, desenvolvem projetos ideológica e politicamente diferentes e muitas vezes opostos, dificultando as possibilidades de diálogo e de decisões comuns para a região.

Não me cabe aqui avaliar a consistência da caracterização ideológica acima referida, apenas apontar sua importância na análise do cenário político que a América do Sul apresenta. É inegável que a presença em seu território de diferentes "esquerdas”, autodefinidas ou não como socialistas, em contraste com outras perspectivas vistas como de "direita” ou "neoliberais", em um contexto em que os Estados que irão governar se movem entre processos de globalização do capital e do poder, conflitos políticos e sociais em nível internacional, regional e doméstico e crescimento desigual de suas economias, traz uma maior complexidade ao processo em questão (SEABRA DA CRUZ JR., 2008).

Conscientes dessas dificuldades, alguns analistas consideram que a criação da Unasul deveria ser o ponto de chegada de um processo prévio de integração entre os países da Comunidade Andina e do Mercosul, acrescidos da Guiana e do Suriname, e não um ponto de largada para um projeto a ser construído. É preciso levar em conta que a integração da América do Sul, para se tornar um objetivo concreto e não retórico ou utópico, vai exigir um trabalho extremamente cuidadoso de aproximação entre seus diferentes blocos e países, na medida em que estes, como já salientamos, ao apresentarem regionalmente grandes assimetrias entre suas economias e divergências marcantes entre muitas de suas propostas políticas, poderiam se tornar um obstáculo para um acordo efetivo em um prazo razoavelmente previsível.

Nesse sentido, se examinarmos comparativamente cada um desses blocos, é visível que os pontos de maior obstrução aparecem com mais nitidez na Comunidade Andina, que tem atualmente como Estados- 
membros a Bolívia, a Colômbia, o Equador e o Peru, países que enfrentam internamente e entre si diferenças ideológicas profundas na orientação de seus projetos políticos, além de desníveis marcantes entre suas economias, assim como diferentes formas de inserção regional e global. ${ }^{3}$

No caso do Mercosul, ainda que os problemas regionais e globais sejam igualmente significativos, assim como as assimetrias econômicas entre seus países-membros, os conflitos político-ideológicos são menores - situação que poderá se modificar com a adesão plena da Venezuela -, uma vez que tendem a ser menos pronunciados, e as identidades de seus cidadãos mais homogêneas. ${ }^{4}$ Contudo, o que pode ocorrer é que, na ausência de uma instância supranacional reconhecida dentro das estruturas administrativas de cada Estado, e dada a falta de normas comuns prévias e claras referentes ao deslocamento de pessoas e ainda o fato de que as fronteiras internas são prioritariamente atravessadas pelos trabalhadores dos países menos desenvolvidos, dificilmente a livre circulação destes na região poderá se tornar uma prática generalizada, como ocorre na União Europeia (UE). Por outro lado, o alto grau de assimetria econômica entre Argentina e Brasil, os dois maiores Estados do bloco, e entre estes e os dois menores, Uruguai e Paraguai, como já foi assinalado, pode gerar medidas protecionistas rígidas que trariam novas dificuldades à abertura de suas fronteiras internas, tanto comerciais quanto ao que se refere à livre circulação de pessoas.

A este quadro, é necessário acrescentar ainda o fato de que o Mercosul está em plena fase de ampliação, uma vez que a Bolívia e o Chile, em 1996, o Peru, em 2003, e a Colômbia e o Equador, em 2004, já se integraram ao bloco como membros associados. No caso da Venezuela, foi-lhe outorgado, na Conferência do Mercosul em Montevidéu no ano de 2005, o status de Estado Associado em Processo de Adesão e, há algum tempo atrás, em 15 de dezembro de 2009, depois de várias tentativas anteriores, o país obteve, com uma vantagem extremamente reduzida, a aprovação pelo Congresso brasileiro de sua incorporação ao bloco como membro pleno, ficando ainda pendente a aprovação do Paraguai. 
De uma maneira ou de outra, o que fica claro nesta discussão é que a América do Sul em geral, e o Mercosul em particular, está diante de uma grave crise em que questões referentes ao emprego, à equidade, à segurança cidadã, à inclusão social e à capacidade integradora, acompanhadas crescentemente por problemas propriamente políticoinstitucionais, obrigam a que se faça uma reflexão séria sobre que novas saídas poderiam ser encontradas para que os processos regionais ou sub-regionais de integração no nosso continente não se tornem apenas retóricos ou, no melhor dos casos, essencialmente comerciais. A complexidade dessa questão reside justamente no que viemos apontando até agora, isto é, na diversidade das dimensões que um processo de integração carrega consigo, uma vez que se trata de criar fórmulas legais comuns para que a pluralidade dos atores que serão incluídos no processo, em especial as pessoas de seus diferentes Estados, possam transitar livremente por todo o território integrado por meio de uma lógica que não seja apenas nacional.

Essa perspectiva nos leva, se é que se pretende refletir seriamente em termos de integração regional, a analisar supranacionalmente os problemas que surgem em cada país, sabendo-se que os desafios que estes se propõem a resolver e os objetivos a alcançar requerem a formação de identidades e de compromissos políticos que transcendam suas fronteiras internas. E isso porque, reafirmando o que já foi sugerido, a livre circulação de trabalhadores em um espaço regional integrado politicamente exige decisões coletivas não separadas por barreiras territoriais, culturais ou de qualquer outra espécie (SIERRA, 2004).

\section{O Modelo Europeu}

Partindo dessa perspectiva, a experiência da União Europeia pode ser altamente esclarecedora, tanto por apontar os caminhos que lhe permitiram avançar na conquista de ganhos sociais importantes, entre os quais a abertura de suas fronteiras internas aos nacionais e não nacionais, como por mostrar outros que a fizerem regredir, como no caso da reação aos imigrantes que, provenientes de países recém-incorporados ou vindos de fora das fronteiras da UE, se dispõem a atravessá-las livremente em busca de trabalho. ${ }^{5}$ 
Neste texto, contudo, não me proponho a analisar em detalhe o tema da livre circulação de pessoas na União Europeia. Quero apenas salientar alguns pontos ligados a essa questão e que podem fazer da experiência europeia um material rico que nos ajuda a pensar que caminhos seguir ou evitar na procura de uma integração de nosso continente do ponto de vista da abertura de suas fronteiras internas (CAMARGO, 1999).

Começo por dizer que o Tratado de Roma de 1958 já previa a situação dos trabalhadores migrantes definidos como pessoas não nacionais que exerciam uma atividade produtiva e que se deslocavam de um país para outro dentro da mesma comunidade à procura de um posto de trabalho. Em seu artigo 48, o Tratado dispunha "que a livre circulação deveria supor a eliminação de qualquer discriminação em razão da nacionalidade dos trabalhadores dos Estados-membros no que se refere ao emprego, à remuneração e às demais condições trabalhistas”. Ficava assim estabelecido que o princípio da livre circulação previa o direito de aceitar ofertas de trabalho, de se deslocar livremente para este fim dentro do território nacional dos Estados-membros, de residir em qualquer um deles para exercer livremente a referida ocupação e de permanecer em seu território após haver ocupado um posto de trabalho (ALENCAR SILVA; ALENCAR SILVA, 2002).

Quero ressaltar, contudo, que a efetiva circulação dos trabalhadores no interior da comunidade europeia não se deu, nesse período, como se esperava, na medida em que as cláusulas acima citadas não tinham regulamentação supranacional, já que eram os próprios Estadosmembros que se encarregavam de buscar a solução dos conflitos. Com o correr do tempo, novos instrumentos modificaram essa situação no sentido de que a preferência por trabalhadores nacionais nas vagas de emprego foi dando lugar à aceitação de trabalhadores estrangeiros desde que a vaga não fosse preenchida por nacionais, passando depois os não nacionais a serem regularmente aceitos, permanecendo, porém, algumas restrições que seriam levantadas em $1^{\circ}$ de janeiro de 2014 (ALENCAR SILVA; ALENCAR SILVA, 2002).

Nesse trajeto, a primeira revisão institucional ocorreu com o Ato Único Europeu, em vigor a partir de $1^{\circ}$ de julho de 1987 e que, antece- 
dendo à assinatura da Carta Comunitária dos Direitos Sociais Fundamentais dos Trabalhadores, em 1989, permitiu a implantação das quatro liberdades básicas, a saber, a livre circulação de bens, pessoas, capitais e serviços. Esta decisão acelerou a constituição de um mercado sem fronteiras que, a partir de $1^{\circ}$ de novembro de 1993, ano em que entrou em vigor o Tratado da União Europeia conhecido como Tratado de Maastricht, passou a funcionar plenamente, propondo-se a desenvolver, entre seus objetivos essenciais, a vertente social da recém-constituída União Europeia (CAMARGO, 2007).

Nesse contexto, uma das grandes inovações do Tratado foi a implantação de uma cidadania europeia paralela à nacional, conferindo, assim, aos europeus em geral, e aos trabalhadores em particular, novos direitos, que enumero a seguir.

- Todo trabalhador da UE, seja qual for o seu lugar de residência, tem o direito de exercer uma atividade por conta de outrem em qualquer Estado-membro, recebendo o mesmo tratamento e usufruindo das mesmas condições de emprego e trabalho que os nacionais daquele Estado. No caso de serem concedidas a uma empresa vantagens provenientes do recrutamento de uma percentagem mínima de trabalhadores nacionais, cidadãos de outros Estados-membros serão equiparados aos nacionais.

- No que se refere especificamente ao recrutamento de trabalhadores, o mesmo princípio de igualdade coloca determinadas exigências que impedem qualquer discriminação que possa dificultar o acesso ao trabalho de cidadãos da UE que não sejam nacionais do Estado de acolhimento. Esses empecilhos podem advir da dificuldade de circulação dentro da União, da promulgação de procedimentos especiais de recrutamento para cidadãos comunitários ou da existência de limites à publicação de ofertas de emprego na imprensa ou em qualquer outro meio de comunicação, ou ainda do estabelecimento de condições para inscrever-se nos serviços de colocação e residência. Quando isso ocorre, a ação discriminatória será considerada sem efeito pelo direito comunitário. 
- Quanto ao emprego no setor público, o mesmo princípio da interdição à discriminação é aplicado entre nacionais e não nacionais, vigorando, contudo, restrições voltadas para certos postos de trabalho do setor público relacionados com o exercício da autoridade pública ou com salvaguardas aos interesses gerais do Estado. Nessas situações, em razão da natureza das tarefas e das responsabilidades, os critérios são avaliados caso a caso.

Ao lado desses avanços, algumas barreiras à entrada de trabalhadores ainda persistem. Refiro-me ao reconhecimento de qualificações, no caso da exigência de fluência em determinadas línguas ou de formação específica em determinada área, fazendo muitas vezes com que estas pessoas se vejam na necessidade de se submeter a uma reclassificação para trabalhar em outro Estado da União. Como solução, a União Europeia criou o "sistema de reconhecimento mútuo de diplomas”, o que faz com que aquele que for qualificado para um determinado domínio em um Estado-membro possa ter a mesma profissão em qualquer outro do bloco nas mesmas condições que os cidadãos locais (EU4JOURNALISTS, 2003-2009).

A essas medidas favoráveis à livre circulação de trabalhadores, acrescenta-se a existência de um Tribunal de Justiça Comunitário cujas competências, previamente estabelecidas, garantem que seu ordenamento deverá ser aplicado em todo o território da União. Dessa maneira, ao se constituir como um instrumento obrigatório para a aproximação das legislações entre os países da região e, simultaneamente, para a incorporação das normas comuns no plano jurídico interno de cada um deles, assegura-se a consolidação e avanço do processo de integração europeia (ALBUQUERQUE, 2000).

Em relação a esse ponto, o Mercosul não contempla em sua estrutura institucional um Tribunal de Justiça Comunitário, preferindo optar por outros mecanismos, como o de solução de controvérsias, ou formas de negociação direta, ou intervenção do Grupo Mercado Comum, ou ainda o procedimento arbitral. No decorrer deste texto, examinaremos alguns desses procedimentos e de seus resultados concretos. 
O Processo de Integração Regional: Fronteiras Abertas para os Trabalhadores do Mercosul

\section{O Mercosul: Origem e Trajetória \\ O Tratado de Assunção}

Tendo feito essas considerações gerais e antes de entrar no tema específico que me proponho a desenvolver, gostaria de fazer uma apresentação rápida da trajetória do Mercosul desde o ponto de vista de seu modelo de integração, o que pode nos ajudar a situar com maior clareza a questão da livre circulação de seus trabalhadores em diferentes momentos de seu trajeto.

Começo por reportar-me aos anos 1960, momento em que o projeto de integração da região latino-americana sob a orientação teórica da Comissão Econômica para a América Latina (CEPAL) apontava para a adoção de um modelo de desenvolvimento integrado que tinha como eixo central uma política de substituição de importações destinada a dar condições para o surgimento de um parque industrial internacionalmente competitivo. Concretamente, o modelo tinha como objetivo a formação de um mercado comum continental que, iniciado com a constituição de uma Associação Latino-Americana de Livre Comércio (ALALC), formalmente estabelecida em 1960 pelo Tratado de Montevidéu, previa a formação gradual de acordos sub-regionais nos marcos do projeto global, entre os quais o Pacto Andino, a Integração Centro-americana e o Caricon, no Caribe. Posteriormente, em 1980, a criação da Associação Latino-americana de Integração (ALADI) arrematou o projeto que fora previsto. Em nenhuma dessas fases, contudo, a preocupação com a questão da livre circulação de trabalhadores esteve presente (CAMARGO, 1992).

De qualquer maneira, a proposta ALALC/ALADI foi interrompida antes de obter os resultados esperados pela instauração de regimes militares em alguns países da região, situação que se prolongou até meados dos anos 1980. Nesse contexto em que governos autoritários foram se estabelecendo de forma não simultânea nos diferentes países, as clivagens políticoideológicas se fortaleceram, acentuando os impasses que já começavam a desgastar os processos de integração: de um lado, governos ainda democráticos, como os do Chile e da Venezuela, olhavam com desconfiança o surgimento de governos autoritários na região; de outro, Argentina e 
Brasil, já sob regimes militares que partilhavam uma mesma visão geopolítica e nacionalista, disputavam a hegemonia do continente (CAMARGO; VASQUEZ OCAMPO, 1988). ${ }^{6}$

Em meados dos anos 1980, com a gradual democratização de parte dos países da região, especificamente do Brasil e da Argentina, o campo parecia livre para a retomada do projeto de integração. Com esse propósito, é criado em 1986 o Programa de Integração e Cooperação Bilateral Argentina-Brasil (PICAB), no marco do qual são assinados, ao longo dos anos 1986/88, 23 protocolos, dos quais o setor mais dinâmico foi o de bens de capital, essencial para a modernização e o desenvolvimento científico-tecnológico do parque industrial nos dois países. As negociações prosseguiram conduzindo ao estabelecimento de vários mecanismos de cooperação entre suas economias e à criação do Grupo Mercado Comum, que, passando a incluir o Paraguai e o Uruguai, permitiu, em 26 de março de 1991, a assinatura do Tratado de Assunção, mediante o qual foi constituído o Mercado Comum do Sul, oficialmente chamado de Mercosul.

Gostaria de salientar que o acordo bilateral Argentina-Brasil fora de natureza essencialmente desenvolvimentista, no qual a ideia de preferências comerciais e de promoção de complementaridades intrassetoriais se confundia com a própria ideia de integração. Esse modelo, contudo, caracterizado como um "regionalismo fechado", não se reproduziu no Mercosul, cujas políticas econômicas, inseridas na conjuntura neoliberal dos anos 1990 e orientadas para a constituição inicial de uma união aduaneira e posteriormente de um mercado comum, ${ }^{7}$ se voltaram na direção de um "regionalismo aberto", estratégia mais bem adequada às exigências de competitividade que, vindas do plano global, traçaram as opções macroeconômicas dos Estados que compunham o bloco e os modelos de regionalismo que pretendiam adotar (CAMARGO, 2006). ${ }^{8}$

Na realidade, o projeto Mercosul, ao se propor a formar um bloco de países que apresentavam pesos diferentes nas arenas regional e internacional, fundamentou-se, como estratégia básica, em uma redefinição das relações regionais nas quais a tradicional rivalidade entre Argentina e Brasil se constituiu como o centro do processo, ao mesmo tempo 
em que os países menores, Paraguai e Uruguai, na ausência de qualquer tratamento diferenciado que harmonizasse as desigualdades, ocuparam uma posição de retaguarda.

Esse modelo, contudo, preocupava os trabalhadores do bloco. Desde os primeiros momentos da constituição do Mercosul, em um pronunciamento público dirigido aos ministros de Trabalho dos quatro países, a Coordenadora das Centrais Sindicais do Cone Sul, ${ }^{9}$ integradas por seis centrais sindicais desses países, lançou uma Carta Social e de Direitos Fundamentais do Mercosul que propunha a ratificação, pelos quatro países, de um pacote de convenções ligadas à Organização Internacional do Trabalho (OIT), instrumento que asseguraria a homogeneização das condições mínimas dos trabalhadores.

Essa iniciativa, ao mesmo tempo que afirmava seu compromisso com a integração, denunciava a ausência, por parte dos governos, de uma opção clara que garantisse "que a transformação da estrutura produtiva não se desenvolveria em prejuízo dos trabalhadores e dos setores populares de qualquer dos países". ${ }^{10}$ As centrais sindicais avaliavam que, em consequência das novas políticas de ajuste e da forte reestruturação produtiva, as taxas de desemprego tenderiam a aumentar e, simultaneamente, a flexibilizar seus direitos enquanto trabalhadores e a diminuir seu poder aquisitivo. Essa avaliação negativa se apoiava na ideia de que alguns dos principais objetivos incorporados ao Tratado, entre os quais a harmonização de políticas e medidas macroeconômicas regionais que tinham como base uma Tarifa Externa Comum e Critérios de Origem, haviam sido, na prática, deixados de lado, ao mesmo tempo em que políticas concretas voltadas para problemas nos mercados de trabalho nacionais decorrentes do princípio de "livre mobilidade de fatores produtivos” nem haviam sido previstas (CASTRO, 1995).

A essas dificuldades, habituais em processos dessa natureza, poderiam ser acrescentadas questões relacionadas com a circulação de mão de obra subcontratada e clandestina entre países menos favorecidos que, ao gerar uma forte discriminação no campo da remuneração e demais condições de trabalho, poderia gerar, em alguns setores, sentimentos nacionais de rejeição a uma futura livre circulação de trabalhadores no 
bloco. Afirmava ainda que a prática de circulação dos trabalhadores na região, sendo bem anterior à criação do Mercosul, exigia, em um contexto de integração, uma regulamentação clara e um tratamento urgente referentes à criação de critérios comuns para solucionar o problema dos deslocamentos intracomunitários relacionados com os direitos humanos e sociais de seus cidadãos.

Partindo desse ponto e levando-se em conta a crescente consolidação e institucionalização dos acordos previstos no Tratado de Assunção, que apontava para a promoção e proteção dos direitos humanos no Mercosul, para a efetivação dos direitos trabalhistas e para a preservação das liberdades fundamentais, os trabalhadores organizados do Mercosul lançaram, em 9 de maio de 1991, a proposta de criação de um espaço institucional alternativo onde pudessem atuar a partir de uma perspectiva essencialmente sindical. Essa proposta se concretizou pela constituição de um subgrupo de trabalho, o $\mathrm{N}^{\circ} 11$, que, ligado especificamente às "Relações Trabalhistas, Emprego e Seguridade Social”, enfatizava a livre circulação de trabalhadores e a identificação das medidas necessárias para alcançá-la, objetivo previsto até dezembro de 1994, momento em que se iniciaria o funcionamento do mercado comum (SANT’ANA, 2000).

\section{O Protocolo de Ouro Preto}

Prosseguindo com a trajetória do Mercosul, três anos depois da assinatura do Tratado de Assunção, definiu-se, no âmbito do Protocolo de Ouro Preto, assinado em dezembro de 1994, a estrutura institucional que deveria consolidar a União Aduaneira prevista no referido Tratado. O documento apresentado aos quatro governos pelas centrais sindicais defendia, como tese central, a "democratização do Mercosul”, não prevendo uma instância supranacional dentro das estruturas administrativas de cada Estado-parte. Em seu lugar, o núcleo funcional do bloco deveria ser administrado pelos setores burocrático-estatais dos quatro governos, com visível exclusão de representação dos interesses dos cidadãos.

De acordo com essa perspectiva, foram mantidos os órgãos e as funções políticas já estabelecidas anteriormente, ao lado de outros orga- 
O Processo de Integração Regional: Fronteiras Abertas para os Trabalhadores do Mercosul

nismos que deveriam dar suporte às questões políticas e às negociações econômicas mais complexas e diversificadas que iriam surgir com a constituição da União Aduaneira e do Mercado Comum (GOUVEIA, 2008). Paralelamente, foi criado, por propostas das centrais sindicais e como instância obrigatória, o Fórum Econômico Social, de caráter consultivo, dotado de autonomia e amplo poder de iniciativa, destinado a facilitar o acesso rápido a informações sobre as decisões tomadas pelos órgãos do Mercosul (CASTRO, 1995).

Abrindo um parêntese, não é demais lembrar que a constituição de um Mercado Comum exige de todos os seus membros, além da presença de benefícios sociais em geral, que o fator trabalho seja especificamente considerado, o que implica que uma série de políticas concretas referentes ao livre deslocamento dos trabalhadores entre os países do bloco sejam implantadas, entre as quais a abolição de barreiras fundadas na nacionalidade, assim como a igualdade de direitos com os nacionais de cada país. Significa ainda assegurar o livre acesso de trabalhadores de um Estado-membro aos postos de trabalho em outros Estados-membros, assim como a garantia de um tratamento paritário em relação aos trabalhadores do lugar onde o serviço tenha sido prestado e a manutenção de uma disciplina previdenciária durante e após a cessão do trabalho. Contudo, o Fórum Econômico e Social recémcriado, que contava em seu início unicamente com a participação de trabalhadores e empresários e que, posteriormente, foi aberto para outros setores organizados e representativos da sociedade, pouco acrescentou às reivindicações até então apresentadas.

Ainda que o Protocolo de Ouro não houvesse atingido todos os objetivos inscritos no Tratado de Assunção, o Mercosul pós-1994 passou a contar com instituições mais consolidadas e de maior abrangência, como o Conselho do Mercado Comum (CMC), seu órgão supremo, o Grupo Mercado Comum (GMC), seu órgão executivo com poder de criar Subgrupos de Trabalho, a Comissão Parlamentar Conjunta, composta por deputados das respectivas Assembleias Nacionais, embrião do futuro Parlamento Mercosul, a Comissão de Comércio do Mercosul (CCM) e o Foro Consultivo Econômico e Social (FCEE), que, em representação dos setores econômicos privados, tanto empresários 
como trabalhadores e consumidores, teve como função elaborar e encaminhar recomendações ao Grupo Mercado Comum. Este órgão, mesmo sendo de caráter meramente consultivo, constituiu um caminho de entrada importante para a participação dos setores sociais, especialmente dos trabalhadores, nas negociações do Mercosul (CASTRO, 2007).

Paralelamente ao Foro Consultivo Econômico e Social, o antigo Subgrupo de Trabalho No. 11, tendo-se tornado depois o No. 10, deslocou o foco de interesse principal da livre circulação dos trabalhadores para a análise dos fenômenos migratórios e para a produção de estatísticas e elaboração de normas (SANT’ANA, 2000). Essa mudança ampliou o espaço de negociação entre os atores sociais públicos e privados, isto é, Ministérios do Trabalho, empregadores e sindicatos, estes últimos com direito a voz, mas não a voto. Nessa fase do processo, a questão da livre circulação de trabalhadores aparecia como uma etapa a ser atingida em algum momento do trajeto.

Outro passo nessa direção foi dado em junho de 1995, quando foi assinado o Protocolo de Assunção sobre Direitos Humanos no Mercosul, documento que incluiu as questões trabalhistas na cartilha dos direitos humanos. Com isso, esse tema se tornou um dos principais desafios para a integração da região, fazendo com que a percepção da existência de grupos socialmente vulneráveis assinalasse a necessidade de articulação de uma política entre os membros do bloco que assegurasse a igualdade de tratamento em seus diferentes estratos sociais.

Partindo dessa perspectiva, em outubro de 1998, no âmbito da XV Reunião do Conselho do Mercado Comum, foi lançada a Declaração Sociolaboral do Mercosul, que, ao reconhecer os direitos humanos como fator imprescindível para a integração e, ao incluir elementos até então ausentes, deu maior flexibilidade às relações trabalhistas. Entre esses elementos, destacam-se:

- a criação de mecanismos de consulta permanentes entre representantes dos governos destinados a facilitar o diálogo social entre os países do bloco; 
- a determinação de que os trabalhadores fronteiriços e migrantes passariam a gozar de um sistema de proteção igual aos nacionais;

- a garantia de que os trabalhadores que se deslocassem entre os Estados-partes teriam direito à Seguridade Social;

- a determinação que os Estados deveriam se comprometer com a formação profissional contínua e permanente como forma de promover uma força de trabalho mais flexível; e

- a previsão de criação de uma Comissão Trabalhista como forma de assegurar que as propostas acima referidas seriam aplicadas (INSTITUTO OBSERVATÓRIO SOCIAL, 2010).

Prosseguindo nesse caminho, foi assinado, em dezembro de 2002, no âmbito da XXIII Reunião do Conselho do Mercosul, o "Acordo sobre Residência para Nacionais dos Estados-partes”, iniciativa que deveria marcar o início de uma nova etapa na história da constituição do bloco, especificamente no domínio da livre circulação de pessoas e da consolidação do mercado comum (KUZNIETZ; BORGES, 2003). Este acordo, negociado no âmbito da Reunião dos Ministros do Interior dos Estados-partes do Mercosul, mais a Bolívia e o Chile, estabelecia que todo o território deveria constituir uma "área de livre residência com direito ao trabalho” para todos os seus cidadãos, sem exigência de outro requisito além da própria nacionalidade, entendendo por isso cidadãos natos ou naturalizados há pelo menos cinco anos.

A esse acordo, ratificado e implementado somente pelo Brasil e Uruguai, ${ }^{11}$ veio juntar-se o Acordo sobre Isenção de Vistos aos Estadospartes do Mercosul, voltado para facilitar a circulação temporária de pessoas físicas e jurídicas nacionais de qualquer dos Estados-membros prestadoras de serviços, podendo cada uma delas entrar em qualquer desses Estados mediante contrato para a realização de atividades remuneradas, prevendo-se uma permanência de dois anos, prorrogável uma vez por igual período. Este visto, contudo, ao qual se juntou “o mecanismo para o exercício profissional temporário” relativo à cooperação entre os conselhos profissionais dos diferentes países do bloco, ${ }^{12}$ e que deveria ter critérios igualitários, limitou-se a favorecer alguns profissionais, como professores, cientistas e técnicos especializados, 
dando-lhes o direito a múltiplas entradas e saídas, em detrimento de trabalhadores menos especializados (CAETANO, 2005).

Mesmo assim, para que esses ganhos pudessem efetivamente se concretizar, seria necessário que o problema da harmonização das legislações prevista no Tratado de Assunção e a redução das assimetrias nas condições de emprego, ambas as questões ligadas intrinsecamente ao custo da mão de obra, fossem previamente solucionadas. Como decorrência, por falta de consenso entre os membros do bloco, o tema da livre circulação dos trabalhadores não consta de forma explícita entre as normas que presidiram a implementação do Mercosul.

Abrindo um novo parêntese, gostaria de dizer que, em relação à harmonização das legislações, questão que já fora salientada no início deste texto, o Mercosul, diferentemente da União Europeia, não possui um Tribunal de Justiça Comunitário com competência para garantir que seu ordenamento deva ser aplicado em todos os países do bloco, constituindo-se como um instrumento obrigatório para a aproximação das legislações entre todos eles e para a incorporação das normas comuns no plano jurídico interno de cada um (ALBUQUERQUE, 2000). Em seu lugar, o que existe no Mercosul é um mecanismo de solução de controvérsias que, iniciado em 1994, não tem caráter institucional e funciona ad hoc, agindo da seguinte forma.

Em sua primeira fase, e de acordo com o Anexo III do Tratado de Assunção, qualquer controvérsia deveria ser resolvida por meio de negociações diretas. Caso o conflito não chegasse a bom termo, seria encaminhado ao Grupo Mercado Comum, que apresentaria uma solução em sessenta dias. Se a situação permanecesse a mesma, o caso seria apresentado ao Conselho do Mercado Comum, que daria seu parecer sobre a disputa.

Em sua segunda fase, depois de algumas alterações posteriores e transitoriamente incorporado ao Protocolo de Brasília, o mecanismo de solução de controvérsias do Mercosul adquire sua forma definitiva em 2004, no âmbito do Protocolo de Olivos, instância que rege atualmente seu funcionamento. Nele, algumas características do sistema original foram mantidas, entre as quais: 
O Processo de Integração Regional: Fronteiras Abertas para os Trabalhadores do Mercosul

- a resolução de controvérsias continuará a ser operada por negociação e arbitragem, inexistindo uma instância judicial supranacional.

- os particulares continuarão dependendo dos governos nacionais para apresentarem suas demandas.

- o sistema continuará sendo provisório e poderá ser modificado quando ocorrer o processo de convergência da tarifa externa comum.

A partir dessa lógica, a principal inovação do Protocolo de Olivos foi a criação do Tribunal Arbitral Permanente de Revisão do Mercosul, composto por cinco árbitros, incluindo um nacional de cada Estadoparte. As demandas deste tribunal são limitadas às questões de direito julgadas pelo Tribunal ad hoc com a presença de três árbitros quando dois Estados estiverem envolvidos ou de cinco quando forem mais de dois. Paralelamente, o referido protocolo faculta às partes escolherem o foro onde se dará o julgamento, evitando assim decisões divergentes de outras organizações internacionais sobre o mesmo assunto (PROTOCOLO DE OLIVOS, 2009).

Retornando à análise do Protocolo de Ouro Preto, o setor trabalhista do Mercosul, representado pela Coordenadora das Centrais Sindicais do Cone Sul, consciente das dificuldades ainda existentes e tendo previsto que poderia ocorrer, nos anos que se seguiriam, uma diminuição das atividades do Subgrupo de Trabalho No. 10 e problemas no funcionamento do Foro Consultivo Econômico-Social, propôs, em 2003, uma nova discussão a respeito. Os principais pontos a serem apresentados deveriam incluir uma "reforma político-institucional para consolidar a supranacionalidade, uma coordenação macroeconômica e social para acelerar a construção de economias produtivas integradas e o aprofundamento dos direitos sociais e trabalhistas". ${ }^{13}$

Paralelamente ao movimento dos setores sindicais, mudanças de governos na região, especificamente no Brasil, com a posse na Presidência de Luis Inácio Lula da Silva, em janeiro de 2003, e de Ernesto Kirchner, na Argentina, em maio de 2003, além do prognóstico da vitória quase certa da Frente Amplia no Uruguai, concretizada em 31 
de abril de 2004 com a eleição de Tabaré Vazquez, assinalavam a possibilidade de definir novas formas de relacionamento entre os seus países, o que significava um avanço no processo negociador do Mercosul, permitindo-lhe posições similares em termos de política externa, e novas prioridades para os temas sociais e trabalhistas. A esperança que esses governos recém-instalados traziam era de que os conflitos que dificultavam a consolidação da União Aduaneira perdessem força, e que se avançasse no caminho da constituição de um verdadeiro mercado comum, com livre circulação de mercadorias, pessoas, capital e serviços. Quanto às negociações externas do Mercosul, o bloco em conjunto se opôs à continuidade das negociações ligadas à ALCA e às propostas comerciais da União Europeia; já no âmbito da Organização Mundial do Comércio (OMC), assumiu uma posição de liderança na articulação das demandas comerciais de uma parte significativa dos países em desenvolvimento (CASTRO, 2007).

No que se refere especificamente ao Brasil, seu governo apresentou, como objetivo concreto na Cúpula do Mercosul de junho de 2003, o "Programa para a Consolidação da União Aduaneira e para o Lançamento do Mercado Comum”, previsto para 2006, documento que propunha a eliminação, em um prazo o mais curto possível, da dupla cobrança da Tarifa Externa Comum (TEC), condição para que se consolidasse a União Aduaneira e se assentassem as bases para a conformação do Mercado Comum. ${ }^{14}$ Em sua agenda interna, questões de grande complexidade e de difícil alcance, e que correspondiam à livre circulação de cidadãos já referidos em documentos anteriores, como as ligadas à residência, ao reconhecimento de qualificações, ao exercício profissional e à prestação de serviços por pessoas físicas, foram novamente incluídas, ao lado de outras prioridades, como as do Paraguai e Uruguai, que se orientavam para o tema polêmico das assimetrias, e a da Argentina, que apontava, como base de uma possível convergência cambial, para a criação de um Instituto Monetário do Mercosul.

No caso das assimetrias, na Cúpula de Ouro Preto, em abril de 2004, os presidentes do Mercosul, por pressão dos dois países menores, Uruguai e Paraguai, assumiram a necessidade de buscar formas efetivas de redu- 
zir as desigualdades estruturais entre os quatro sócios. Com esse objetivo, foi criado em 2006 um Fundo para a Convergência Estrutural do Mercosul (FOCEM), destinado a financiar programas de apoio às economias menores e às regiões menos desenvolvidas nas áreas de habitação, saneamento, energia, transporte e capacitação tecnológica, iniciativa que contribuiria para o fortalecimento do processo de integração (AMORIM, 2008). Quanto à proposta oficial do governo argentino de unificação monetária entre os países do Mercosul e que deveria iniciarse entre Brasil e Argentina, críticas na imprensa e na opinião pública dificultaram uma decisão favorável a respeito. Entre as objeções, apontavam-se os seguintes argumentos: em primeiro lugar, a natureza prematura da proposta, na medida em que uma moeda comum só poderia ser adotada depois de uma maior integração, isto é, quando a formação da área de livre comércio estivesse concluída e quando houvesse maior harmonização das legislações nos campos trabalhista, tributário e de mercado de capitais; e, em segundo, a avaliação de que os interesses do Brasil e da Argentina não eram convergentes entre si.

Contudo, nesse encontro em Ouro Preto, alguns avanços na área trabalhista ocorreram, entre os quais a convocação, pela Comissão do Mercado Comum, da Primeira Conferência Regional de Emprego, constituída pelos ministros do Trabalho, empregadores e sindicatos que apresentaram uma recomendação orientada para a implantação de medidas que facilitassem a criação de postos de trabalho no âmbito do Mercosul. Com esse objetivo, foi criado o Grupo de Alto Nível de Emprego, que, destinado a fortalecer a articulação entre os Ministérios de Economia, Produção, Desenvolvimento e Planejamento, deveria impulsionar a integração das políticas macroeconômicas, comerciais, educacionais e demais políticas de Estado. Paralelamente, nessa ocasião, encomendou-se à Comissão Parlamentar Conjunta a redação de uma proposta de Protocolo Constitutivo do Parlamento do Mercosul, que, assinado na Cúpula de Presidentes, em 2005, deu lugar, em dezembro de 2006, à constituição do referido Parlamento, finalmente instalado em Montevidéu, em maio de 2007.

Ainda em 2005, a implantação do Acordo Multilateral de Seguridade Social, assinado pelos quatro países do bloco em 1997 e idealizado 
inicialmente em uma Comissão do SGT-10 voltada para a análise dos sistemas previdenciários dos quatro países-membros visando gerar propostas que melhorassem seu desempenho, afetou positivamente a agenda social do Mercosul. É preciso lembrar que, sendo o Mercosul caracterizado como uma União Aduaneira imperfeita, os trabalhadores que emigravam não possuíam regulamentação previdenciária que legitimasse seus deslocamentos, o que os tornava sujeitos a uma precária inserção no mercado de trabalho dos países-membros para os quais se deslocavam e a uma posição inferior em sua escala socioprofissional. Contudo, o fato de que a iniciativa proposta, assim como todos os demais mecanismos do bloco previamente existentes cujas disposições eram aplicáveis em todo o território do Mercosul, tivesse e ainda tenha um caráter intergovernamental, não estando, portanto, acima dos países que o constituem, fez com que estes tendessem a centralizar suas decisões nos altos cargos políticos de cada um deles, dificultando com isso a participação de outros atores da sociedade, como sindicatos, subgrupos de trabalho, organizações sociais etc.

Mesmo assim, apesar dessas limitações, o Acordo Multilateral de Seguridade Social, ao se constituir como um elemento de regularização, harmonização e convergência entre as legislações dos Estados constitutivos do bloco, contribuiu para que seus trabalhadores e familiares pudessem ter seus direitos relativos à seguridade social garantidos quando mudassem de país para cumprir funções laborais. Isso significava que, quando um trabalhador e sua família migrassem, lhe seriam dados, ao chegar ao lugar de destino, os mesmos direitos e deveres dos cidadãos nativos, entre os quais o direito à residência, que, assinado em 2002, só entrou em vigor em agosto de 2006, e o direito à aposentadoria, que passou a representar a soma dos tempos de serviço prestados nos diferentes países, recebendo a contribuição em cada país em que o trabalhador exercesse seu ofício.

Essas iniciativas, mesmo com todas as dificuldades e omissões que ainda enfrentam, representam uma mudança significativa no fortalecimento do Mercosul, especialmente no que se refere à livre circulação de pessoas físicas, já que estas poderão residir com toda sua família e trabalhar legalmente em outro país, seja como trabalhadores com 
O Processo de Integração Regional: Fronteiras Abertas para os Trabalhadores do Mercosul

carteira de trabalho assinada ou como empreendedores independentes por um prazo de dois anos. Vencido esse prazo, poderão obter a residência permanente se demonstrarem que podem se sustentar financeiramente (GOUVEIA, 2008).

Isso aparece com clareza na proposta de constituição de um Programa Mercosul Social e Participativo, instituído por decreto do presidente Lula em 6 de outubro de 2008, iniciativa que se propôs a intensificar as relações entre o governo e a sociedade civil no campo da integração regional. Para tanto, foi criado um conselho composto por instituições da sociedade civil voltadas para esse tema, cuja primeira reunião se deu em Brasília, presidida pelo ministro das Relações Exteriores, Celso Amorim, com a presença de diversos funcionários do Estado. Nessa ocasião, foi lançado, no âmbito do referido programa, um conjunto de diretrizes que, tendo como eixo os temas de cidadania, participação, direitos humanos, diversidade e saúde, cobrem a pluralidade de questões que passarão a ser discutidas. No que se refere à livre circulação de trabalhadores, quatro ações foram destacadas:

1) assegurar a todos os cidadãos da região o direito à residência e ao usufruto de benefícios e facilidades nos territórios de todos os Estados-partes e associados do Mercosul, mediante trâmite simplificado para regularização migratória e obtenção de permissão de residência;

2) avançar no reconhecimento de diplomas e certificados de formação emitidos por entidades nacionais de ensino e formação profissional transfronteiriços;

3) facilitar o exercício profissional temporário e permanente como forma de ampliar as oportunidades de emprego dos trabalhadores em um espaço regional integrado; $\mathrm{e}$

4) avançar na integração da proteção social dos Estados-partes e Associados do Mercosul com destaque para os sistemas de proteção previdenciária, de saúde, de assistência social e de trabalho.

A isso, deve-se acrescentar a entrada em vigor de uma legislação em matéria de reconhecimento de diplomas, decisão aprovada em uma 
reunião do Conselho do Mercado Comum realizada em Montevidéu em dezembro de 2009. Segundo essa decisão, o diploma por estudos realizados no exterior para ter validade no Brasil deverá, além de exigir o reconhecimento por universidade brasileira que tenha curso de pós-graduação reconhecido pela Coordenação de Aperfeiçoamento de Pessoal de Nível Superior (CAPES), ser na mesma área de conhecimento e em nível de titulação equivalente ou superior. Da mesma maneira, estudantes que se afastarem do Brasil para cursarem mestrado ou doutorado no exterior com bolsas concedidas pela própria CAPES e por outras agências brasileiras deverão passar pelo mesmo processo de reconhecimento (NUNES, 2007).

Não é fácil, contudo, apostar em que tudo isso será atingido, especialmente no que se refere à livre circulação dos fatores produtivos, especificamente dos trabalhadores, sobretudo se nos lembrarmos que o Mercosul, depois de quase vinte anos de vigência, ainda permanece na fase de uma União Aduaneira imperfeita que, apoiando-se basicamente em sua dimensão econômico-comercial, está longe de haver alcançado, na prática, a forma clássica de um Mercado Comum, como fora previsto no Tratado de Assunção em 1991.

Com efeito, o cenário que temos pela frente não parece favorável a um avanço no que se refere às questões sociais e aos processos de integração entre países em desenvolvimento. Não podemos deixar de pensar que, em uma conjuntura de crise econômica mundial da dimensão da que está ocorrendo e em um contexto de globalização do capital que tem como epicentro a competitividade entre os países mais ricos, aqueles que não possuem uma estrutura produtiva para fazer frente aos mercados dominantes serão obrigados a reestruturar seus parques industriais, o que torna mais difícil a livre circulação de seus trabalhadores (BOTEGA; PEDROSO, 2008).

Diante desse panorama, o quadro que se apresenta no caso do Mercosul é de grande incerteza. De um lado, temos economias complexas como Brasil e Argentina, e do outro, economias com menor nível de desenvolvimento, como Uruguai e Paraguai, situação que vai exigir um maior equilíbrio no processo de reestruturação produtiva que pos- 
O Processo de Integração Regional: Fronteiras Abertas para os Trabalhadores do Mercosul

sa assegurar a todos os cidadãos do bloco benefícios sociais equivalentes. Se acrescentarmos a isso a exigência de um marco comum de regulação do trabalho que venha a corrigir a disparidade existente entre as legislações trabalhistas desses países, assegurando assim a todos os seus trabalhadores as mesmas oportunidades de acesso ao trabalho e à residência e a livre circulação entre suas fronteiras, a tarefa torna-se ainda mais complexa. Como conclusão, o que podemos acrescentar a esta análise é que a integração entre os países sulamericanos não é apenas uma escolha entre outras e sim uma condição para que o desenvolvimento da região, em termos de Estado e sociedade, não fique pelo meio do caminho.

\section{Notas}

1. Um mercado comum implica a livre circulação de bens, serviços, fatores produtivos e pessoas. Contudo, o Tratado de Assunção, ao não contemplar de forma categórica o direito de livre circulação de pessoas, restringindo-se às liberdades de circulação de capitais, de bens e serviços, definiu essa etapa de formação do Mercosul como um período de consolidação da União Aduaneira, fase não totalmente concluída.

2. A ideia de se criar uma zona de livre comércio continental surgiu em 2004 em uma rodada de negociações em que se discutiu a entrada do México no grupo. Nessa ocasião, foi assinada a Declaração de Cuzco, que tinha como base a união do Mercosul e do Pacto Andino.

3. Na Comunidade Andina, o corte se dá entre, de um lado a Bolívia, governada por Evo Morales, e o Equador, por Rafael Correia, situados à esquerda do espectro; e, do outro, mais à direita, o Peru e a Colômbia, governados respectivamente por Alan Garcia e Uribe.

4. Do ponto de vista político, tanto o Brasil, governado até pouco tempo por Luis Inácio Lula da Silva, quanto a Argentina, por Ernesto Kirchner, e o Uruguai, até recentemente por Tabaré Vazquez, considerados como de esquerda ou centroesquerda, convergem em seu compromisso com a integração entre seus países. Já no que se refere ao Paraguai, com um passado prolongado e recente de golpes e tentati- 


\section{Sonia de Camargo}

vas de golpe de Estado, assassinatos políticos, prisões e demissão de governantes, elege para presidente, em 2008, Fernando Lugo, ex-bispo católico, fortemente nacionalista que, tendo já assinalado conflitos com empresas brasileiras situadas em seu território, pode vir a ser uma fonte de dificuldades para o Mercosul.

5. No caso dos trabalhadores dos países que entraram para a UE em 2004, ainda que não possam mais ser discriminados na base da nacionalidade, eles ainda enfrentam restrições que estão detalhadas no Tratado de Adesão: durante um período de transição de dois a sete anos, período que varia de Estado para Estado, lhes é exigida uma autorização para que possam ser recrutados. No caso dos que foram incorporados em 2007, como Romênia e Bulgária, as restrições no mercado de trabalho serão levantadas em $1^{\circ}$ de janeiro de 2014.

6. No Chile, o golpe militar do general Augusto Pinochet, que derrubou o governo democrático de Salvador Allende, ocorreu em 1973, nove anos depois do início do ciclo de governos militares no Brasil, em 1964. Em 1966, a Argentina, por sua vez, iniciou um período de governos militares, interrompido em começo dos anos 1970 com a volta do peronismo ao poder, e reproduzido em 1976 com o golpe militar do general Gualtiere.

7. A União Aduaneira consiste em uma série de medidas que visam harmonizar as políticas comerciais do Mercosul em relação a terceiros. $\mathrm{O}$ alicerce que sustenta esta união é a Tarifa Externa Comum (TEC), que se aplica na forma de uma série de taxas de importação comuns aos quatro países nos produtos vindos de fora. O Mercado Comum, por sua vez, implica a livre circulação entre os Estados-membros de bens, serviços, capital e mão de obra, não havendo obstáculos relacionados com a circulação de seus cidadãos, e espera-se uma harmonização legislativa em questões trabalhistas e previdenciárias.

8. "Regionalismos abertos”, perspectiva adotada pelos teóricos da CEPAL nos anos 1990, indicando com isso uma maneira de conciliar "disciplina determinada pela abertura das economias com o tratamento preferencial aos produtos da região”. Ver El regionalismo abierto: América Latina y el Caribe en la economia internacional. Documento da CEPAL, 24 mai. 1996.

9. A Coordenadora das Centrais do Cone Sul, criada em 1987, só depois do Tratado de Assunção desenvolveu uma prática mais efetiva.

10. Logo após a formação do Mercosul, as centrais sindicais de seus quatro países, por intermédio da Coordenação das Centrais Sindicais do Cone Sul, formaram uma 
rede que se constituiu como a principal articulação social presente nas discussões do Mercosul.

11. O Acordo entre a República Federativa do Brasil e a República Oriental do Uruguai para implementação entre si do Acordo sobre Residência para Nacionais dos Estados Partes do Mercosul foi aprovado pelos respectivos Congressos Nacionais e ratificado pelos seus governos em dezembro de 2002. Quatro anos depois, em março de 2006, os ministros de Estado e de Justiça desses dois países assinam uma portaria relativa à implantação entre si do referido acordo, únicos países em que o acordo tem vigência.

12. Acordo para a criação do "visto Mercosul” XXX CMC - Montevidéu, 15/XII/03.

13. Apesar dos avanços no que se refere a novas formas de relacionamento entre os países do Mercosul e de posições convergentes em termos de política externa, o objetivo de supranacionalidade não foi uma questão nem mesmo abordada.

14. A constituição de uma União Aduaneira, que deveria servir de base para a consolidação do mercado comum, objetivo principal do acordo Mercosul, que implicaria na livre circulação de bens, serviços, fatores produtivos e pessoas, não atinge até o momento sua forma plena, sendo ainda definida como uma União Aduaneira imperfeita.

\section{Referências Bibliográficas}

ALBUQUERQUE, Fabiola Santos. A livre circulação dos trabalhadores: análise comparativa - Mercosul e União Europeia. 2000. Disponível em: <http://jus.uol. com.br/revista/texto/1618/a-livre-circulacao-dos-trabalhadores-analise-compa rativa-mercosul-e-uniao-europeia>. Acesso em: 11 out. 2010.

ALENCAR SILVA, Osvaldo; ALENCAR SILVA, Renata Cristina de Oliveira. A livre circulação de pessoas e trabalhadores e o processo de integração no Mercosul, 2002. Disponível em: <http://jus2.uol.com.br/doutrina/texto.asp?id=4013>. Acesso em: 11 out. 2010. 
AMORIM, Celso. Discurso do ministro de Relações Exteriores do Brasil, XII Sessão Ordinária do Parlamento do Mercosul, 18 ago. 2008. Disponível em: $<$ http://www.itamaraty.gov.br/sala-de-imprensa/discursos-artigos-entrevistas-eoutras-comunicacoes/embaixador-celso-luiz-nunes-amorim/discurso-do-ministrodas-relacoes-exteriores-celso>. Acesso em: 11 out. 2010.

BOTEGA, Leonardo da Rocha; PEDROSO, Márcia Naiar Cerdote. A integração nos marcos da reestruturação produtiva: os dilemas do Mercosul. Revista Espaço Acadêmico, n. 83, abr. 2008.

CAETANO, Gerardo. Internacional: a Cúpula de Ouro Preto. Portal da Fundação Perseu Abramo, 2005. Disponível em: <http://www.fpabramo.org.br/o-quefazemos/editora/teoria-e-debate/edicoes-anteriores/internacional-cupula-de-ouropreto>. Acesso em: 11 out. 2010.

CAMARGO, Sonia de. A integração do Cone Sul: 1960-1990. Contexto Internacional, ano 5, n. 9, jan./jun. 1992.

. União Europeia - uma referência indispensável para o Mercosul. Contexto Internacional, v. 21, n. 1, jan.-jun. 1999.

. Mercosul: crise de crescimento ou crise terminal? Lua Nova, n. 68, 2006.

. Europe debates its destiny. BraziliScience Review, mai. 2007. Disponível em: <http://www.bpsr.org.br/english/arquivos/BPSR_v1_n1_march2007 _05.pdf>. Acesso em: 11 out. 2010.

; VASQUEZ OCAMPO, José Maria. Autoritarismo e democracia na Argentina e Brasil. Uma década de política exterior. São Paulo: Editora Convivo, 1988.

CASTRO, Maria Sílvia Portela de. Reflexos do Mercosul no mercado de trabalho. São Paulo em Perspectiva, v. 9, n. 1, jan.-mar. 1995.

. Mercosul: frente e verso. 2007. Disponível em: <http://actravcourses.itcilo.org/es/a2-01275/a2-01275-presentations/silvia-portela/mercosulfrente-e-verso/at_download/file>. Acesso em: 11 out. 2010.

EU4JOURNALISTS. Mercado interno. Livre circulação de pessoas. European Journalism Center. 2003-2009. Disponível em: <http://www.eu4journalists. eu/index.php/dossiers/portuguese/C4448>. Acesso em: 11 out. 2010. 
O Processo de Integração Regional: Fronteiras Abertas para os Trabalhadores do Mercosul

GOUVEIA, Luana. A influência do Acordo de Seguridade Social do Mercosul no mercado de trabalho brasileiro sub-regional. In: XVI Encontro Nacional de Estudos Populacionais, ABEP, Caxambu, 29 set. 2008.

INSTITUTO OBSERVATÓRIO SOCIAL. 2010. Disponível em: <http://www. observatoriosocial.org.br/>. Acesso em: 11 out. 2010.

KUZNIETZ, Gabriel; BORGES, Agnes Pinto. A livre circulação de pessoas entre diferentes países. 2003. Disponível em: <http://www.conjur.com.br/2003-mar21/livre_circulacao_pessoas_entre_diferentes_paises>. Acesso em: 11 out. 2010.

PROTOCOLO de Olivos para a Solução de Controvérsias no Mercosul. In: Sistema de Informação sobre Comércio Exterior, Cap. VII, 2009. Disponível em: <http://www.sice.oas.org/trade/mrcsr/olivos/polivos_p.asp>. Acesso em: 11 out. 2010.

NUNES, Alceu Ferreira. A validade dos diplomas obtidos nos países do Mercosul. 2007. Disponível em: <http://jus2.uol.com.br/doutrina/texto.asp?id=10101>. Acesso em: 11 out. 2010.

ROMERO, Roberto. O nascimento da Unasul e seus desafios. The Blogger, 25 mai. 2008. Disponível em: <http://www.cartamaior.com.br/templates/materia Mostrar.cfm?materia_id=15014>. Acesso em: 11 out. 2010.

SANT’ANA Marcílio Ribeiro de. A livre circulação de trabalhadores no Mercosul. In: Brasil: migrações internacionais e identidade. 2000. Disponível em: <http://www.comciencia.br/reportagens/migracoes/migr08.htm>. Acesso em: 11 out. 2010.

SEABRA DA CRUZ JR., Ademar. Fazendo o caminho ao andar: aportes introdutórios para a caracterização da esquerda latino-americana no começo do século XX. In: SOARES DE LIMA, M. R. (Org). Desempenho de governos progressistas no Cone Sul: agendas alternativas ao neoliberalismo. Rio de Janeiro: Edições Iuperj, 2008.

SIERRA, Gerónimo de. Las matrices societales en crisis, pero ahora en contexto Mercosur. In: ; BERNARDES ALVARADO, M. (Comp.). Democracia, gobernanza y desarrollo en el Mercosur. Hacia un proyecto proprio en el siglo XXI. Montevidéu: UNESCO/CLACSO, 2004. 
Resumo

\section{O Processo de Integração Regional: Fronteiras Abertas para os Trabalhadores do Mercosul}

O que me proponho neste trabalho é discutir o tema da livre circulação dos trabalhadores no Mercosul, levando-se em conta que esta liberdade - diferentemente de outras que aparecem como objetivos essenciais a serem alcançados no processo de integração desta sub-região - não faz parte do texto do Tratado de Assunção, assinado em março de 1991. Esta ausência é reveladora, na medida em que a liberdade de circulação de pessoas constitui um dos elementos que evidencia com maior clareza a existência de um processo de integração, na medida em que afeta diretamente a vida dos cidadãos assegurando seu livre trânsito dentro do bloco e oportunidades iguais entre os nacionais e não nacionais. No texto do referido Tratado, a integração aparece limitada à circulação de capitais, bens e serviços, liberdade assegurada pela eliminação de qualquer medida que possa prejudicá-la. Partindo dessa discussão, pretendo examinar quais os avanços institucionais já alcançados no sentido da criação de políticas que, concretamente, conduzam à abertura de fronteiras entre os países do Mercosul por meio das quais seus cidadãos - neste caso, os trabalhadores - possam se deslocar livremente e residir em seu local de trabalho. Para tanto, acredito que conhecer a experiência da União Europeia possa ser de grande utilidade.

Palavras-chave: Mercosul - Integração Regional - Livre Circulação de Trabalhadores - Direito de Residência - Direitos Fundamentais no Trabalho

\section{Abstract}

\section{The Process of Regional Integration: Open Borders for Mercosul Workers}

My proposal for this article is to discuss the free mobility of workers inside the Mercosul block, bearing in mind that this liberty, in the contrary of others issues that arise as essential aims to be reached in the integration process of the region, wasn't incorporated in the Assunção Treaty, signed in march 1991. This absence 
O Processo de Integração Regional: Fronteiras Abertas para os Trabalhadores do Mercosul

is revealing in the sense that the liberty of circulation of persons is one of the elements that show with more evidence the existence of an integration process as it affects directly the life of its citizens ensuring their free displacement inside the region and equal opportunities among nationals and no nationals. In the text of the above-mentioned Treaty, integration appears only in reference to the circulation of capital, goods and services, being this liberty safeguarded by the elimination of any obstacle which could damage this road. Enlarging this discussion, I intend to look up what institutional advances has been reached in the course of the process, in the sense of the inclusion of measures which lead to the opening of the borders of Mercosul countries through which its citizens - in our case, the workers - could move with liberty and could live in the place where they work. To discuss this point, I believe that the knowledge of European experience is of great utility.

Keywords: Mercosul - Regional Integration - Free Circulation of Workers - The Right of Domicile - Fundamental Labor Rights 